\title{
BLOOD GLUCOSE METABOLISM, SERUM, AND URINE OSMOLALITY IN RESPONSE TO SODIUM-ENRICHED ACACIA HONEY DRINK CONSUMPTION DURING REHYDRATION AFTER EXERCISE IN HOT AND HUMID ENVIRONMENT
}

\author{
NUR SYAMSINA AHMAD ${ }^{1}$, MOHAMMED SAAT ISMAIL ${ }^{1}$, MAHANEEM MOHAMED $^{2}$ AND \\ FOONG KIEW OOI*1
} ${ }^{1}$ Exercise and Sports Science Programme, School of Health Sciences, ${ }^{2}$ Department of Physiology, School of Medical Sciences,
Universiti Sains Malaysia, 16150, Kubang Kerian, Kelantan, Malaysia.

*Corresponding author: fkooi@usm.my

Submitted final draft: 16 January 2020

Accepted: 10 February 2020

http://doi.org/10.46754/jssm.2020.07.008

\begin{abstract}
This study investigated the effectiveness of sodium-enriched Acacia honey drink as a post-exercise recovery aid on physiological parameters in the hot and humid environment $\left(31^{\circ} \mathrm{C}, 70 \%\right.$ relative humidity). Ten male recreational athletes (age: $21.8 \pm 1.4$ years, $\mathrm{VO}_{2 \max }: 51.5 \pm 4.1 \mathrm{~mL} \cdot \mathrm{kg}^{-1} \cdot \mathrm{min}^{-1}$ ) participated in this randomized cross-over study. In running trial before the rehydration phase (Run-1), participants were required to run on a treadmill at $65 \% \mathrm{VO}_{2 \max }\left(7.7 \pm 0.75 \mathrm{~km} . \mathrm{h}^{-1}\right)$ in the heat for $60 \mathrm{~min}$. Participants had a fluid replacement with either plain water $(\mathrm{W})$, Acacia honey drink $(\mathrm{H})$ or sodium-enriched Acacia honey drink (HS) with an amount equivalent to $150 \%$ of body weight loss in three boluses (60\%, 50\% and 40\% respectively) immediately at $0 \mathrm{~min}, 30 \mathrm{~min}$ and $60 \mathrm{~min}$ during two-hour rehydration phase. Blood and urine samples were collected and two-way repeated measure ANOVA was used for statistical analysis. Participants' body weight in W, H, and HS trials dropped after running for $60 \mathrm{~min}$. Plasma volume changes showed significant reductions with W: $7.2 \pm 3.4 \%(p<0.05), \mathrm{H}: 6.6 \pm 3.4 \%(p<0.05)$, and HS: $6.6 \pm 4.2 \%$ $(p<0.001)$ at the end of the run. During the rehydration phase, there were significantly $(p<0.05)$ higher levels of plasma glucose, plasma insulin, serum osmolality and urine osmolality in $\mathrm{H}$ and HS compared to W. Both $\mathrm{H}$ and HS drinks can be recommended as a recovery aid.
\end{abstract}

Keywords: Sodium-enriched acacia honey, honey, exercise, glucose, insulin.

\section{Introduction}

Prolonged exercise in the heat can challenge the limits of human temperature regulation, body fluid and aerobic performance (Cheuvront et al., 2010). This condition is also associated with fatigue, glycogen depletion and hypoglycemia (Nybo, 2008). It has been reported that consuming supplementation or drinks containing carbohydrate $(\mathrm{CHO})$ during post-exercise is crucial for the enhancement of sport performance (Ahmad et al., 2015; Beck et al., 2015; Naclerio et a1., 2017; Peeling et al., 2018). Ingestion of fluid containing $\mathrm{CHO}$ can prevent dehydration (Bandelow et al., 2010) and a decline in blood glucose (Burke et al., 2011). It is suggested that $\mathrm{CHO}$ be taken in the first two hours after exercise to allow the fast rate of glycogen synthesis (Beelen et al., 2010). The previous study found that the monosaccharide of $\mathrm{CHO}$, fructose, is beneficial for the replenishment of glycogen (Peinado et al., 2013). Consumption of fructose during recovery can increase the restoration of endogenous glycogen stores (Gonzalez et al., 2017). The fructose contained in natural sources such as honey produces beneficial effects by maintaining a higher osmolality of blood effectively compared to plain water (Cheuvront et al., 2004). The mixture of fructose, glucose, and sucrose ingestion resulted in approximately $65 \%$ higher exogenous $\mathrm{CHO}$ oxidation rates compared to glucose ingestion alone (Jentjens \& Jeukendrup, 2005). Exogenous CHO oxidation rate reached a value of $1.75 \mathrm{~g} / \mathrm{min}$ whereas previously it was thought that a $1 \mathrm{~g} / \mathrm{min}$ was the absolute maximum (Jeukendrup, 2010). Honey contains $75 \%$ of multiple transportable 
CHO such as fructose, glucose, sucrose, and maltose which lead to increased fluid delivery, thus gastrointestinal distress may be diminished. Among types of honey in Malaysia, Acacia honey contains the highest amount of $\mathrm{CHO}$ compared to Lavender and Chestnut honey (Cotte et al., 2003). As shown in Table 1, Acacia honey used in the present study contains several types of CHO, i.e. fructose, sucrose, glucose and maltose.

Honey can be ingested in the fluid. The amount of fluid should be directly proportional to sweat loss or close to it to maintain important physiological functions (Mack \& Nadel, 2011). Carbohydrate can be ingested in a bolus feeding or dispersed in the interval. If water is consumed, the volume ingested needs to exceed the fluid deficit by approximately $150 \%$ to compensate for the urinary losses that occur with water ingestion (Sharp, 2006; Shirreffs \& Evans et al., 2017). During prolonged exercise especially in the heat, the body loses a large amount of water through sweating. It was reported that a $1 \%$ to $4 \%$ decrease in body weight may occur if plasma volume decreased by $10 \%$ (Hall et al., 2012). Decrease plasma volume level that accompanies dehydration and high body temperature can disturb the physiological activity in the body (Nybo, 2008). It also leads to difficulty in maintaining high blood flow to muscle and skin and consequently may reduce heat loss and resulting in a rise in core temperature (Wingo et al., 2010).

Apart from $\mathrm{CHO}$, sodium intake also plays a role during rehydration. The sodium content of Acacia honey from Malaysia is high and near to sesame honey from Egypt and multifloral honey from India (Moniruzzaman et al., 2013). Sodium intake is important especially during rehydration because it could induce body water conservation (Rokova et al., 2017), which subsequently will reduce urinary output, increase the rate of fluid restoration for fluid balance and glycogen replenishment (Rehrer, 2001). Evans et al. (2009) suggested that for rehydration purpose, hypertonic glucose-sodium drinks may be more effective at restoring and maintaining hydration status after sweat loss. The study also found that the participants remained euhydrated for one-hour longer with sodium-enriched glucose drink containing $25 \mathrm{mmol} / \mathrm{L}$ of sodium with $10 \%$ glucose than sodium-enriched glucose drink containing $25 \mathrm{mmol} / \mathrm{L}$ of sodium with $2 \%$ glucose. Similarly, beneficial effect on rehydration as reported by Evans et al (2009) was also observed in our present study in which the sodium-enriched Acacia honey drink in our study contained $50 \mathrm{mmol} / \mathrm{L}$ of sodium with $22.9 \%$ glucose. Rehydration beverage should contain at least 30 to $50 \mathrm{mmol} / \mathrm{L}(1.7$ to $2.9 \mathrm{~g} \mathrm{NaCl} / \mathrm{L}$ ) of sodium to achieve effective rehydration following exercise (Wong \& Chen,

Table 1: Composition of Acacia honey drink and sodium-enriched honey drink

\begin{tabular}{lc}
\hline Composition of honey & Amount in $\mathbf{1 0 0} \mathbf{m l}$ \\
\hline Acacia honey & \\
Energy (kcal) & 302.0 \\
Carbohydrate (g) & 75.0 \\
$\quad$-Fructose g) & 31.2 \\
$\quad$-Glucose (g) & 22.9 \\
$\quad$-Sucrose (g) & 9.9 \\
$\quad$ - Maltose (g) & 3.3 \\
Protein (g) & 0.5 \\
Fats (g) & $<0.1$ \\
Sodium (Na) (mg) & 13.0 \\
Sodium-enriched honey drink & \\
Additional sodium in sodium-enriched honey drink & \\
(mmol/L) & 50.0 \\
\hline
\end{tabular}


2011). If there is a sufficient amount of sodium in the beverage, even a small amount of $\mathrm{CHO}$, i.e. $2 \%$, may improve the rate of intestinal uptake of sodium and water (Jeukendrup, 2010). The effectiveness of sodium as recovery aid could also be seen in a sodium-enriched coconut water study (Ismail et al., 2007). It was hypothesised that Acacia honey which contains multiple types of $\mathrm{CHO}$ such as fructose, sucrose, glucose, and maltose when combined with sodium, may elicit more beneficial effects compared to glucose alone-sodium drink as reported by previous studies of Jeukendrup (2010) and Ismail et al. (2007).

To our knowledge, to date, the effectiveness of sodium-enriched Acacia honey drink as a post-exercise recovery aid on physiological parameters such as blood glucose, insulin, cortisol, serum osmolality, plasma volume, urine osmolality, urine volume, tympanic body temperature, and body weight changes in the heat has not been well investigated. If the present study can confirm the beneficial effects of sodium-enriched Acacia honey drink on physiological parameters, thus it can be proposed to the athletes for enhancing their sports performance in the hot and humid environment.

\section{Materials and Methods}

\section{Participants}

Ten young male athletes who were able to run on the treadmill (Full vision INC, TMX425CP, USA) at $65 \% \quad \mathrm{VO}_{2 \max }$ (maximal oxygen consumption) for at least 60 min were recruited in for this study. The participants were involved in sports competitions at the university, club or state level. The inclusion criteria of the participants were male, aged between $18-25$ years, healthy and physically active, trained or exercised at least three times per week $30 \mathrm{~min}$ per session. The exclusion criterion was on medication. Participants were asked to refrain from ingesting any products containing honey for 48 hours before the main trials. They received explanations about the study procedures before giving their consent. This study was approved by the Human Research Ethics Committee, Universiti Sains Malaysia, (USMKK/PPP/ JEPeM [228.3.(04)]).

\section{Preparation of Honey Drinks}

The honey used in the study was Acacia honey. The honey was extracted from the same source and was used without additional processing and treatment before administration. Acacia honey composition was analysed by the Laboratory of the Department of Molecular Medicine in Universiti Malaya. Energy, $\mathrm{CHO}$ and mineral content of Acacia honey are shown in Table 1. The variability in $\mathrm{CHO}$ and mineral content may be dependent on the floral preference of the honeybee, from which protein and colloids are derived, and the presence of enzymes, which are from the honeybees themselves (Alvarez-Suarez et al., 2010).

Regarding the preparation of the honey drink, $6.8 \%$ concentration of $\mathrm{CHO}$ in the honey drink needs to be prepared. This concentration is equivalent to the concentration of $\mathrm{CHO}$ in commercially available sport drinks such as 100PLUS, ISOMAX, and Gatorate drinks which contain $8.8 \%$ of $\mathrm{CHO}$. Acacia honey contains $75 \mathrm{~g}$ of $\mathrm{CHO}$ per $100 \mathrm{ml}$ of honey, and $100 \mathrm{ml}$ honey drink should contain $6.8 \mathrm{ml}$ of honey $(6.8 \%$ concentration of $\mathrm{CHO}$ in the honey drink). We considered that $6.8 \mathrm{~g}$ of honey contains $6.8 \mathrm{ml}$ of CHO. Thus, $272 \mathrm{~g}$ of Acacia honey was needed to add in $3000 \mathrm{ml}$ of plain water for obtaining $6.8 \%$ concentration of $\mathrm{CHO}$. Meanwhile, for preparing a sodium-enriched honey drink, the prepared honey drink was added with an additional $50 \mathrm{mmol} / \mathrm{L}$ of sodium concentration which is equivalent to $8.7 \mathrm{~g}$.

\section{Experimental Design}

This was a randomised cross-over study. Participants were required to perform three different trials with either plain water (W), honey $(\mathrm{H})$ or sodium-enriched honey (HS) drinks in each trial. The trials were separated by a one-week interval. The prepared $\mathrm{W}, \mathrm{H}$ and HS drinks were kept cool in a refrigerator 
at temperature $\sim 4^{\circ} \mathrm{C}$ before being consumed. Participants were required to run on a treadmill at $65 \% \mathrm{VO}_{2 \max }\left(7.7 \pm 0.75 \mathrm{~km} \cdot \mathrm{h}^{-1}\right)$ in the heat $\left(31^{\circ} \mathrm{C}, 75 \%\right.$ humidity) for $60 \mathrm{~min}$ (Run-1). Participants had a fluid replacement with either $\mathrm{W}, \mathrm{H}$ or HS with an amount equivalent to $150 \%$ of body weight loss in three boluses $(60 \%, 50 \%$, and $40 \%$ respectively) immediately at $0 \mathrm{~min}, 30$ min, and 60 min during two-hour rehydration phase. Participants' tympanic temperature, body weight, plasma volume, plasma glucose, plasma insulin, plasma cortisol, serum osmolality, urine volume, and urine osmolality were measured.

\section{Preliminary Measurement}

Participants were required to perform two preliminary tests, i.e. a $16 \mathrm{~min}$ incremental submaximal treadmill running test to determine the relationship between running speed and oxygen uptake, and an uphill incremental maximal treadmill running test to exhaustion to determine each participant's maximum oxygen uptake $\left(\mathrm{VO}_{2 \max }\right)$. From the data obtained in the submaximal running test and $\mathrm{VO}_{2 \max }$ test, the speed which elicited $50 \% \mathrm{VO}_{2 \max }$ and $65 \%$ $\mathrm{VO}_{2 \max }$ of the participants were calculated.

\section{Main trial}

Participants reported to the laboratory at 8 a.m after a 10-hour overnight fast. The following procedures were carried out before the commencement of each trial: (i) a standardised breakfast and $500 \mathrm{ml}$ of plain water ingestion; (ii) determination of nude body weight; (iii) cannulation for blood samples drawing, (iv) reheat the heat chamber room to reach $31^{\circ} \mathrm{C}$ and $75 \%$ humidity (controlled by bathtub) and; (v) urine sample taking. All participants performed two trials i.e. $60 \mathrm{~min}$ of running trial before the rehydration phase which was identified as Run-1 and followed by a two-hour rehydration phase. Immediately before the warm-up of Run1 , blood samples were collected. Subsequently, participants were required to warm-up for $5 \mathrm{~min}$ by running at $50 \% \mathrm{VO}_{2 \max }$. Immediately after the completion of the warm-up, the intensity of running was increased to $65 \% \mathrm{VO}_{2 \max }$. In Run-1, a blood sample was collected at $0 \mathrm{~min}$ and at the end of the 60 min run. After completing Run-1, the participants were weighed to determine the amount of body weight loss. Participants were required to rest by sitting on a chair for two hours in the rehydration phase. During the two-hour rehydration period, participants consumed either $\mathrm{W}, \mathrm{H}$ or HS with an amount equivalent to $150 \%$ of body weight loss in three boluses $(60 \%, 50 \%$, and $40 \%$ respectively) at $0 \mathrm{~min}, 30 \mathrm{~min}$, and 60 min. The drinks were given in random order to the participants. Blood and urine samples were taken every 30 min during the rehydration phase. Participants' final body weight was recorded at the end of the rehydration phase.

\section{Anthropometry Measurement}

The participants' body weight (kg) was measured by using a Bioimpedance analyser (Tanita, Japan). Body height ( $\mathrm{cm}$ ) was measured by using a stadiometer (SECA, Germany). Body mass index (BMI) was derived from the calculation of $\mathrm{BMI}=$ Bodyweight $(\mathrm{kg}) /$ height $^{2}$ (m)

\section{Tympanic Temperature Measurement}

Tympanic temperature was measured using digital infrared ear thermometer (Microlife AG 9435 Heerbrugg, Switzerland). The infrared tympanic membrane sensor was designed to primarily detect the infrared radiation emanating from the tympanic membrane. The infrared probe was equipped with a silicon mould to fit into the ear. The probe was gently introduced into the ear canal to correctly position the probe towards the tympanic membrane. All participants' ear canals were cleaned to remove any visible hair and cerumen before taking measurements. All measurements were done in the left ear.

\section{Blood Collection and Analysis}

A cannula (G-15, Venflon) was inserted in an antecubital vein by a medical officer. Before and after warm-up, immediately after Run-1, and every $30 \mathrm{~min}$ during the rehydration phase, $4 \mathrm{ml}$ of venous blood was drawn from the participants. One ml of the blood was transferred into an EDTA 
(Ethylenediamine tetra-acetic acid) tube and was used to measure the hematocrit level. Hematocrit was determined by micro-hematocrit centrifuge and Hawksley Reader (Hawksley England) in duplicate. The percentage change in plasma volume was calculated based on the results of hematocrit (Van Beaumont et al., 1981). Two ml of blood were transferred into an anticoagulant natrium fluoride tube. After centrifugation at $3000 \mathrm{rpm}$ for $10 \mathrm{~min}$ at $4^{\circ} \mathrm{C}$, plasma was transferred into the $1.5 \mathrm{ml}$ tube and stored at -40 ${ }^{\circ} \mathrm{C}$ for analysis of glucose, insulin, and cortisol. Plasma glucose and insulin concentrations were determined using a spectrophotometer (Spekol 1200, Germany) and insulin EIA kits (enzyme immunoassay, US), respectively. Another $1 \mathrm{ml}$ of blood was transferred into a plain tube and was then separated by centrifuge. Serum was stored at $-20^{\circ} \mathrm{C}$ for analysis of serum osmolality. Serum osmolality was analysed by using a cryoscopic osmometer (Osmomat 030, Gonotec, Germany).

\section{Urine Collection and Analysis}

Urine samples were collected at $0 \mathrm{~min}, 30$ min, $60 \mathrm{~min}, 90 \mathrm{~min}$, and $120 \mathrm{~min}$ during the rehydration period. Urine volume was measured using a measuring cylinder, while urine osmolality was measured by using a cryoscopic osmometer (Osmomat 030, Gonotec, Germany).

\section{Statistical Analysis}

All data were reported as mean $\pm \mathrm{SD}$. A twoway repeated measures ANOVA was used to determine differences of blood and urine parameters within and between trials. A significant difference demonstrated in the twoway repeated measures ANOVA was followed by the analysis of the post-hoc Benferroni test. All statistical analyses were performed using the Statistical Package for Social Sciences (SPSS) Version 24.0 (SPSS, Inc., Chicago, IL). Statistical significance was set at $p<0.05$.

\section{Results \\ Anthropometric Characteristic of the Participants}

A total of 10 male athletes completed the study. The physical characteristics of the participants and average running speed are shown in Table 2. All participants completed running on the treadmill at $65 \% \mathrm{VO}_{2 \max }\left(7.7 \pm 0.75 \mathrm{~km} \cdot \mathrm{h}^{-1}\right)$ in the heat $\left(31^{\circ} \mathrm{C}, 75 \%\right.$ humidity) for $60 \mathrm{~min}$.

\section{The Total Amount of Fluid Consumed, Urine Produced and Net Fluid Balance}

The mean of the total amount of fluid consumed during rehydration and total urine produced in each trial are shown in Table 3. The amount of drink consumed by participants in boluses of $60 \%$ of body weight loss was W: $540 \pm 209.8$ $\mathrm{ml}, \mathrm{H}: 558 \pm 229.9 \mathrm{ml}$ and HS: $492 \pm 164.4 \mathrm{ml}$; $50 \%$ of body weight loss was W: $450 \pm 174.8 \mathrm{ml}$, $\mathrm{H}: 465 \pm 191.6 \mathrm{ml}$ and HS: $410 \pm 137.0 \mathrm{ml}$; and $40 \%$ of body weight loss was W: $360 \pm 139.8 \mathrm{ml}$, H: $372 \pm 153.2 \mathrm{ml}$, and HS: $332 \pm 110.0 \mathrm{ml}$. The volume of fluid ingested during the dehydration

Table 2: Physical characteristics of the participants

\begin{tabular}{|c|c|}
\hline Variables & Mean \pm SD \\
\hline Age (years) & $21.8 \pm 1.4$ \\
\hline Weight (kg) & $59.9 \pm 7.8$ \\
\hline Height (cm) & $171.6 \pm 9.0$ \\
\hline BMI & $20.3 \pm 2.2$ \\
\hline $\mathrm{VO}_{2 \max }(\mathrm{ml} / \mathrm{kg} / \mathrm{min})$ & $51.7 \pm 4.1$ \\
\hline Running speed at $65 \% \mathrm{VO}_{2 \max }\left(\mathrm{km} \cdot \mathrm{h}^{-1}\right)$ & $7.7 \pm 0.75$ \\
\hline
\end{tabular}

Note: Data were expressed as mean (SD). BMI, body mean index; $\mathrm{VO}_{2 \max }$, maximum oxygen uptake; W, plain water; $\mathrm{H}$, honey; HS, sodium-enriched honey; $\mathrm{N}=10$ 
phase was not significantly different between trials. Different total urine volume for each trial was observed in the rehydration phase. There were significant differences between the trials $\left(\mathrm{F}_{2,18}=4.216, p<0.05\right)$. Following up a significant difference between trials, the urine output in $\mathrm{W}$ group $(p<0.05)$ was significantly higher compared to HS, resulting in lower cumulative urine volume in HS than W and H. Percentage fluid retention reflected these differences between trial: $51.0 \pm 16.4 \%(\mathrm{~W}), 61.6 \pm 22.4 \%$ $(\mathrm{H})$, and $64.6 \pm 30.8 \%$ (HS). However, no significant differences were observed for fluid retention between all the trials.

Net fluid balance was calculated from the change in body weight, fluid ingested and urine produced. No significant difference in net fluid balance was observed between trials following Run-1. A higher overall net fluid balance was maintained during the rehydration phase in $\mathrm{H}$ and $\mathrm{HS}$ compared to $\mathrm{W}$, with no difference between $\mathrm{H}$ and $\mathrm{HS}$. The net fluid balance remained positive in all trials.

\section{Tympanic Temperature}

Tympanic temperature increased significantly from rest ( $0 \mathrm{~min}$ ) to the end of Run-1 in W (36.1 \pm 0.4 to $\left.36.9 \pm 0.6^{0} \mathrm{C}, p<0.001\right), \mathrm{H}(36.0 \pm 0.4$ to $\left.37.0 \pm 0.7^{\circ} \mathrm{C}, p<0.05\right)$ and $\mathrm{HS}(36.0 \pm 0.4$ to $\left.36.8 \pm 0.4^{\circ} \mathrm{C}, p<0.05\right)$. At the end of rehydration phase, tympanic temperature significantly decreased compared to the time point at the end of Run-1 in all the three trials, i.e. $36.9 \pm$ $0.6^{\circ} \mathrm{C}$ to $36.1 \pm 0.4^{0} \mathrm{C}(p<0.05)$ in $\mathrm{W}, 37.0 \pm$ $0.7^{\circ} \mathrm{C}$ to $36.2 \pm 0.4^{\circ} \mathrm{C}(p<0.05)$ in $\mathrm{H}$ and 36.8 $\pm 0.5^{\circ} \mathrm{C}$ to $36.2 \pm 0.4^{0} \mathrm{C}(p<0.05)$ in HS trials. The tympanic temperature returned to resting values in all three trials after rehydration. There were no significant differences in this measured parameter between the $\mathrm{W}, \mathrm{H}$ and HS trials.

\section{Body Weight Changes}

The average percent body weight loss after 60 min dehydration exercise was $1.50 \pm 0.5 \%$, $1.54 \pm 0.5 \%$, and $1.38 \pm 0.4 \%$ compared to preexercise body weight. The body weight after 60 min dehydration exercise was $58.31 \pm 7.7 \mathrm{~kg}$ in $\mathrm{W}, 58.57 \pm 7.7 \mathrm{~kg}$ in $\mathrm{H}$ and $59.02 \pm 7.8 \mathrm{~kg}$ in HS. The rehydrated body weight after two hours of rehydration was $58.96 \pm 8.0 \mathrm{~kg}$ in W, $59.28 \pm 8.1$ $\mathrm{kg}$ in $\mathrm{H}$, and $59.08 \pm 7.9 \mathrm{~kg}$ in HS. The difference between pre-body weight and rehydrated body weight was $-0.25 \pm 0.2 \mathrm{~kg}$ in $\mathrm{W},-0.16 \pm 0.3 \mathrm{~kg}$ in $\mathrm{H}$ and $-0.12 \pm 0.03 \mathrm{~kg}$ in HS.

\section{Plasma Volume Changes}

Figure 1 illustrated the results of plasma volume changes. In the present study, plasma volume decreased significantly during Run-1 [W: 7.2 $\pm 3.4 \%(p<0.05), \mathrm{H}: 6.6 \pm 3.4 \%(p<0.05)$, HS: $6.6 \pm 4.2 \%(p<0.001)]$, and increased significantly after rehydration [W: $5.0 \pm 6.4 \%(p$ $<0.001), \mathrm{H}: 2.7 \pm 6.7 \%(p<0.001)$, HS: $4.2 \pm$ $3.1 \%(p<0.001)]$ in all the three trials. There were no statistically significant differences in plasma volume between $\mathrm{W}, \mathrm{H}$, and HS trials during the rehydration phase.

Table 3: The mean of the total amount of fluid intake, total urine volume, net fluid balance and percentage of water retention during rehydration in each trial

\begin{tabular}{llll}
\hline Variables & W & H & HS \\
\hline $\begin{array}{l}\text { The total volume of fluid consumed } \\
(150 \% \text { of fluid loss) }(\mathrm{ml})\end{array}$ & $1350.0 \pm 524.4$ & $1395.0 \pm 574.7$ & $1234.0 \pm 411.0$ \\
Total urine produced (ml) & $655.5 \pm 346.7^{*}$ & $458.5 \pm 179.3$ & $383.5 \pm 287.6$ \\
Net fluid balance (ml) & $694.5 \pm 330.2$ & $936.5 \pm 588.1$ & $850.5 \pm 535.6$ \\
Fluid retention (\%) & $51.0 \pm 16.4$ & $61.6 \pm 22.4$ & $64.6 \pm 30.8$ \\
\hline
\end{tabular}

Note: Data were expressed as mean (SD). W, plain water; H, honey; HS, sodium-enriched honey; $\mathrm{N}=10$. * Significantly different from the value in $\mathrm{W}$ trial at $\mathrm{p}<0.05$ 


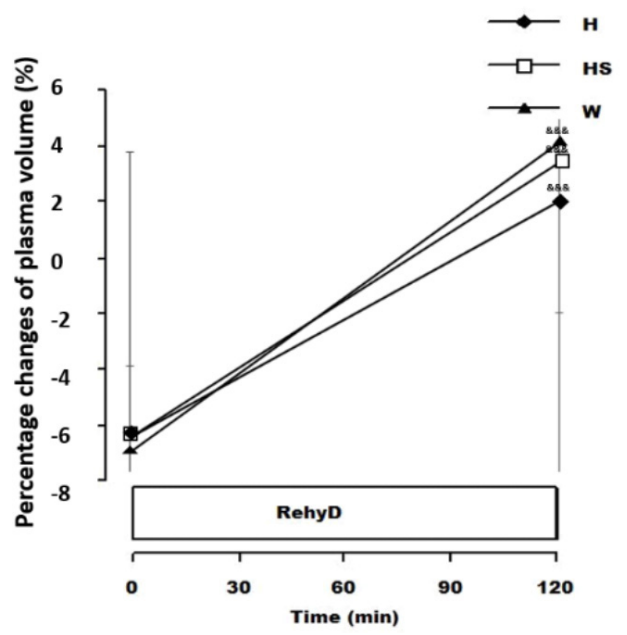

Figure 1: Plasma volume changes during rehydration of plain water (W), honey $(\mathrm{H})$ and sodium-enriched honey (HS) trials. RehyD, Rehydration phase; $\mathrm{N}=10$

\&\&\& Significantly different from respective end of Run-1 $(p<0.001)$ respectively

\section{Serum Osmolality, Urine Osmolality and Urine Volume}

Figure 2 illustrates the results of serum osmolality, urine osmolality and urine volume during rehydration. Both $\mathrm{H}$ and $\mathrm{HS}$ elicited statistically significant $(p<0.05)$ greater values of serum osmolality compared to $\mathrm{W}$ during the rehydration phase (Figure 2A). Even though there was no statistically significant difference in serum osmolality between $\mathrm{H}$ and HS, HS showed a slightly higher serum osmolality level than $\mathrm{H}$ during rehydration. HS also showed a higher level of serum osmolality than $\mathrm{H}$ starting from $60 \mathrm{~min}$ to $120 \mathrm{~min}$ during rehydration.

Generally, urine osmolality showed the trends of increase and then decrease by time for all three trials, (Figure 2B). In general, both $\mathrm{HS}$ and $\mathrm{H}$ showed significantly higher urine osmolality than $\mathrm{W}$ during rehydration. Urine volume showed the trends of decrease and then increase over time during the rehydration phase in all the three trials, with a more significant increase in $\mathrm{W}$ than $\mathrm{H}$ and $\mathrm{HS}$ (Figure 2C). There were no significant differences in urine volume between $\mathrm{W}, \mathrm{H}$, and $\mathrm{HS}$.

\section{Plasma Glucose, Insulin and Cortisol}

Blood glucose, insulin, and cortisol changes are shown in Figure 3. Blood glucose concentration showed the trend of decrease in Run-1 generally in all three trials. The concentration of plasma glucose in $\mathrm{H}$ and $\mathrm{HS}$ increased significantly $(p<$ 0.05 ) until 30 min during the rehydration phase and the concentration reduced until the end of the rehydration phase. The trend of decrease in plasma glucose was observed in $\mathrm{W}$. There were statistically $(p<0.05)$ higher levels of plasma
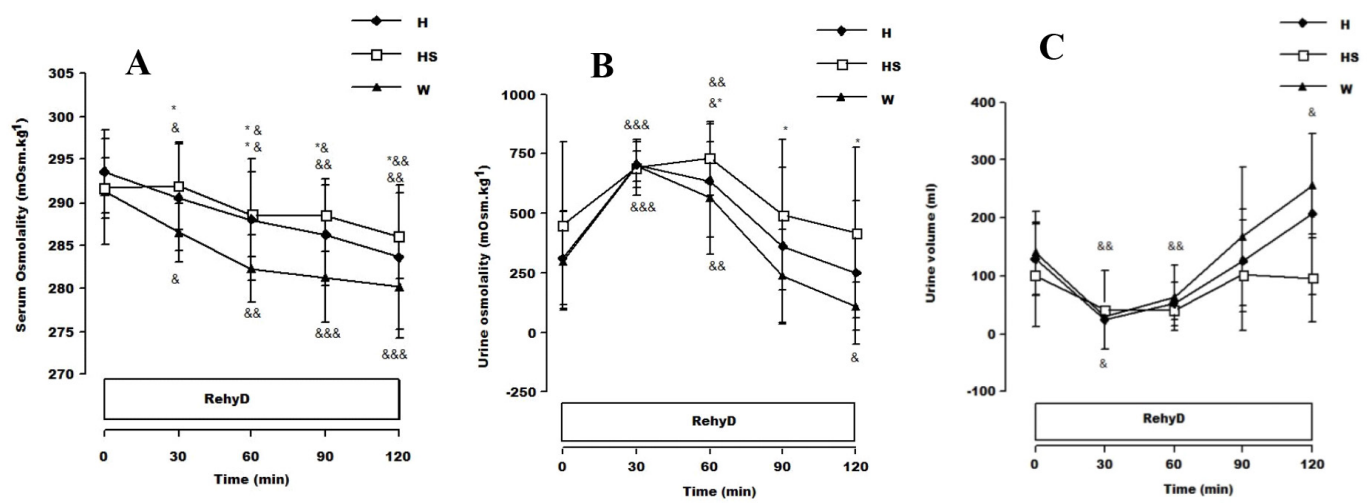

Figure 2: (A)Serum osmolality (mOsm. $\left.\mathrm{kg}^{-1}\right)$; (B) Urine osmolality (mOsm. $\mathrm{kg}^{-1}$ ); and (C) Urine volume $(\mathrm{ml})$ during rehydration of plain water $(\mathrm{W})$, honey $(\mathrm{H})$, and sodium-enriched honey $(\mathrm{HS})$ trials. RehyD, Rehydration phase; $\mathrm{N}=10$

\&, \&\&, \&\&\& Significantly different from respective end of Run-1 at $p<0.05, p<0.01$ and $p<0.001$ respectively.

\# Significantly different from the rehydration phase at $p<0.05$

* $\quad$ Significantly different from the corresponding value in $\mathrm{W}$ trial at $p<0.05$ 

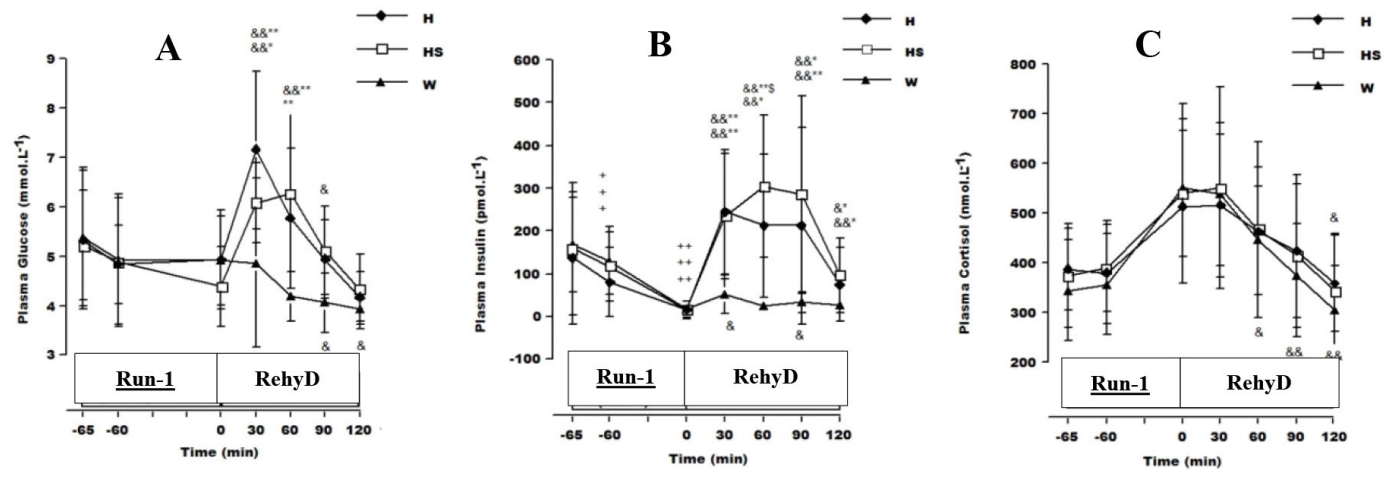

Figure 3. (A) Plasma glucose concentration (mmol.L-1), (B) Plasma insulin (pmol.L-1), and (C) Plasma cortisol (nmol.L ${ }^{-1}$ ) during Run-1, and rehydration of plain water $(\mathrm{W})$, honey $(\mathrm{H})$ and sodium-enriched honey (HS) trials. Run-1, Running trial before the rehydration phase. RehyD, Rehydration phase; $\mathrm{N}=10$

\&, \&\& Significantly different from the respective end of Run-1 at $p<0.05$ and $p<0.01$ respectively.

$*, * *$ Significantly different from the corresponding value in $\mathrm{W}$ trial at $p<0.05$ and $p<0.01$ respectively.

,+++ Significantly different from respective resting values (at rest) at $p<0.05$ and $p<0.01$ respectively

glucose in $\mathrm{H}$ and $\mathrm{HS}$ than $\mathrm{W}$ at $30 \mathrm{~min}$ and 60 min during the rehydration phase. Plasma insulin reduced significantly $(p<0.01)$ to below resting values at the end of Run-1 in the three trials. As observed in plasma glucose, plasma insulin concentration increased significantly $(p<0.05)$ after Run-1 until 90 min during the rehydration phase in $\mathrm{H}$ and $\mathrm{HS}$.

Plasma insulin concentration reduced from 90 min until the end of this phase. The changes in plasma insulin in $\mathrm{W}$ were not as obvious as in $\mathrm{H}$ and HS. There were statistically significant $(p<0.05)$ higher levels of plasma insulin in $\mathrm{H}$ and $\mathrm{HS}$ than $\mathrm{W}$ throughout the rehydration phase. There were no significant differences in cortisol concentration at any time point between all the three trials. Plasma cortisol concentration showed the trend of increase from 0 min until 60 min during Run-1 and subsequently reduced until the end of the rehydration phase.

\section{Discussion}

The results of the study indicated that consumption of Acacia honey drink and sodiumenriched Acacia honey drink have potential in preventing the athletes from heat stress, dehydration, hypoglycemia and imbalance of fluid in the body. This is based on the observation that there were higher levels of plasma glucose, plasma insulin, serum osmolality and urine osmolality in both Acacia honey drink and sodium-enriched Acacia honey drink compared to plain water.

In terms of glucose level, the present study found that blood glucose dropped and no significant difference was observed in plasma glucose between the $\mathrm{W}, \mathrm{H}$ and HS trials after Run-1. During the rehydration phase, plasma glucose in $\mathrm{H}$ and $\mathrm{HS}$ increased significantly as fast as $30 \mathrm{~min}$ from resting value and reduced to a normal level at the end of the rehydration phase. The plasma glucose level in the $\mathrm{W}$ trial was lower than the resting value throughout the rehydration phase. These observations imply that honey could increase plasma glucose, but not plain water. The $\mathrm{CHO}$ contained in Acacia honey drink with $31.2 \%$ of fructose, $22.9 \%$ of glucose, and $9.9 \%$ of sucrose may have played its role for increasing plasma glucose level, especially during the initial stage of rehydration phase. According to Jentjens and Jeukendrup (2003), the rapid phase of muscle glycogen synthesis is characterised by an exerciseinduced translocation of glucose transporter carrier protein-4 to the cell surface, leading to increased permeability of muscle membrane to glucose. This is also related to the functions 
of gastric emptying and intestinal absorption rates, as well as the insulinogenic potential of the CHO (Ormsbee et al., 2014). A higher level of glucose potently stimulates the homeostasis process (Gropper \& Smith, 2012) and brings the glucose level to a normal level after two hours.

Regarding blood insulin, no significant changes were observed in serum insulin in $\mathrm{W}$ trial during the rehydration phase implying that $\mathrm{W}$ did not affect serum insulin. In the present study, the Acacia honey used had shown its potential to elicit a higher level of serum insulin concentration generally compared to $\mathrm{W}$. It is speculated that the compositions of fructose, glucose, and sucrose contained in Acacia honey are appropriate for maintaining a high level of blood glucose and subsequently high level of insulin level during rehydration phase in $\mathrm{H}$ trial. A previous study done by Judelson et al. (2008) also found a significantly higher level of serum insulin concentration during the first stage of the rehydration phase to match the rise of glucose level in the blood. A higher level of glucose potently stimulates glycogenesis activity for the homeostasis process (Gropper \& Smith, 2012). Insulin level increased and then decreased generally by time in the rehydration phase in the $\mathrm{H}$ trial. It was mentioned in Burke et al. (2016) that the rate of muscle glycogen storage may be influenced by muscle glucose uptake and insulin sensitivity. The increased serum insulin level may contribute to the transport of $\mathrm{CHO}$ to the muscle for replenishing muscle glycogen at the early stage of the rehydration phase. Reduction of insulin level at the later stage of the rehydration phase may ensure the maintenance of the high level of plasma glucose, by storing blood glucose as an energy booster. Cortisol is an indicator of stress. Cortisol level increased at the end of Run-1 for all three trials after 60 min treadmill running in the heat, and reflecting that exercise may have served as a type of stress.

James et al. (2015) suggested that electrolyte restriction might have contributed in reducing exercise capacity in the heat. The moderate amount of sodium, i.e. $50 \mathrm{mmol} / \mathrm{L}$ in $150 \%$ bolus was sufficient to raise the plasma volume compared to 23 and $61 \mathrm{mmol} / \mathrm{L}$ (Shirreffs et al., 1996). In the study, plasma volume decreased significantly during the running phase in all the trials. After the ingestion of $\mathrm{W}, \mathrm{H}$, and HS plasma volumes were significantly increased in all three trials. These results imply that $\mathrm{W}, \mathrm{H}$, and HS were equally effective for restoring plasma volume after exercise-induced dehydration. Plasma volume change was calculated by using hematocrit values. In fact, hemoglobin can also be used for calculating plasma volume change. Unfortunately, hemoglobin analysis was not performed and it was considered a limitation of this study.

Regarding plasma osmolality, it was observed that $\mathrm{H}$ and HS drinks ingestion elicited greater values of serum osmolality compared to $\mathrm{W}$ during the rehydration phase, implying that both honey drink without additional sodium and honey drink with additional sodium could maintain serum osmolality better than plain water. Evans et al. (2000) and Hoffman \& Stuempfle (2015) mentioned that fluid replacement with the addition of sodium to a rehydration solution is beneficial for the maintenance of fluid balance due to its effects on extracellular fluid osmolality and volume. The proper amount of sodium helped the participants avoid losing a high amount of water after ingestion.

Acacia honey contains $130 \mathrm{mg}$ of sodium in one liter of honey. An additional of $2.9 \mathrm{~g} / \mathrm{L}$ $(50 \mathrm{mmol} / \mathrm{L})$ of sodium added in one litre of honey in HS did not provide much difference in serum osmolality compared to honey drink without sodium in the present study. The results revealed that honey drink with $130 \mathrm{mg}$ of sodium was sufficient to produce similar hydration conditions as a sodium-enriched drink to promote osmotic stimulus for absorption (Wilson \& Temple, 2003).

In the study, it was found that urine volume decreased and then increased over time in $\mathrm{W}, \mathrm{H}$, and HS trials and the highest urine volume was measured in $\mathrm{W}$ trial compared to at the end of Run-1. It showed that $\mathrm{H}$ and $\mathrm{HS}$ caused higher water retention in the body than $\mathrm{W}$. W trial 
displayed the largest body weight difference $(-0.25 \pm 0.2 \mathrm{~kg})$ between pre-body weight and rehydrated body weight even though all the participants consumed a similar amount of drinks during rehydration. It is speculated that the participants might have lost more water through urine with plain water ingestion. Baker \& Jeukendrup (2011) mentioned that the ingestion of plain water can enhance the urine output and cause a reduction in the drive to drink. The absence of sodium in the plain water will also dilute sodium content in the body and subsequently increase urine osmolality due to kidney clearance mechanisms (Popli et al., 2014). This phenomenon was supported by a lower level of $(p<0.05)$ urine osmolality during $\mathrm{W}$ trial at the end of the rehydration period. The higher level of urine osmolality observed with HS $(419.0 \pm 358.6 \mathrm{mOsm} / \mathrm{kg})$ compared to $\mathrm{H}$ $(249.5 \pm 301.9 \mathrm{mOsm} / \mathrm{kg})$ and $\mathrm{W}$ trial $(110.1 \pm$ $100.3 \mathrm{mOsm} / \mathrm{kg}$ ) may be due to the beneficial effect of sodium contained in the honey drink for conserving body water.

\section{Conclusion}

Rehydration with Acacia honey and sodiumenriched Acacia honey drink elicited greater beneficial effects on physiological parameters especially blood glucose, insulin and osmolality, and urine osmolality compared to plain water in the heat. Thus, both these drinks can be recommended to be used as an ergogenic aid for rehydration purposes in athletes who train and compete in the hot and humid environment.

\section{Acknowledgments}

We would like to express our gratitude to An-Nur Benut Pontian Company Malaysia for sponsoring the acacia honey, and also Assoc. Prof. Siti Amrah for her assistance in arranging - for this sponsorship. This study was financially supported by a Short Term Grant provided by Universiti Sains Malaysia (304/ PPSP/61310058).

\section{References}

Ahmad, N. S., Ooi, F. K., Ismail, M. S. \& Mohamed, M. (2015). Effects of postexercise honey drink ingestion on blood glucose and subsequent running performance in the heat. Asian Journal of Sports Medicine, 6(3), e24044.

Alvarez-Suarez, J. M., Tulipani, S., Díaz, D., Estevez, Y., Romandini, S., Giampieri, F., Damiani, E., Astolfi, P., Bompadre, S. \& Battino, M. (2010). Antioxidant and antimicrobial capacity of several monofloral Cuban honeys and their correlation with color, polyphenol content and other chemical compounds. Food and Chemical Toxicology, 48, 2490-2499.

Baker, L. B., \& Jeukendrup, A. E. (2011). The optimal composition of fluid $\square$ replacement beverages. Comprehensive Physiology, 4,575-620.

Bandelow, S., Maughan, R., Shirreffs, S., Ozgünen, K., Kurdak, S., Ersöz, G., Binnet, M. \& Dvorak, J. (2010). The effects of exercise, heat, cooling and rehydration strategies on cognitive function in football players. Scandinavian Journal of Medicine \& Science in Sports, 20, 148-160.

Beck, K. L., Thomson, J. S., Swift, R. J. \& Von Hurst, P. R. (2015). Role of nutrition in performance enhancement and postexercise recovery. Open Access Journal of Sports Medicine, 6, 259-267.

Beelen, M., Burke, L. M., Gibala, M. J. \& Van Loon, L. J. (2010). Nutritional strategies to promote post-exercise recovery. International Journal of Sports Nutrition and Exercise Metabolism, 20, 515-532.

Burke, L. M., Hawley, J. A., Wong, S. H. \& Jeukendrup, A. E. (2011). Carbohydrates for training and competition. Journal of Sports Sciences, 29, 17-27.

Burke, L. M., van Loon, L. J. \& Hawley, J. A. (2016). Postexercise muscle glycogen resynthesis in humans. Journal of Applied Physiology, 122(5), 1055-1067. 
Cheuvront, S. N., Carter Iii, R., Montain, S. J., Stephenson, L. A. \& Sawka, M. N. (2004). Influence of hydration and airflow on thermoregulatory control in the heat. Journal of Thermal Biology, 29, 471-477.

Cheuvront, S. N., Kenefick, R. W., Montain, S. J. \& Sawka, M. N. (2010). Mechanisms of aerobic performance impairment with heat stress and dehydration. Journal of Applied Physiology, 109, 1989-1995.

Cotte, J. F., Casabianca, H., Chardon, S., Lheritier, J. \& Grenier-Loustalot, M. F. (2003). Application of carbohydrate analysis to verify honey authenticity. Journal of Chromatography A, 1021, 145155.

Evans, G. H., Shirreffs, S. M. \& Maughan, R. J. (2009). Post-exercise rehydration in man: the effects of osmolality and carbohydrate content of ingested drinks. Nutrition, 25, 905-913.

Evans, G. H., James, L. J., Shirreffs, S. M. \& Maughan, R. J. (2017). Optimizing the restoration and maintenance of fluid balance after exercise-induced dehydration. Journal of Applied Physiology, 122(4), 945-951.

Gonzalez, J., Fuchs, C., Betts, J. \& Van Loon, L. (2017). Glucose plus fructose ingestion for post-exercise recovery-greater than the sum of its parts? Nutrients, 9(4), 344-359.

Gropper, S. S. \& Smith, J. L. (2012). Advanced Nutrition and Human Metabolism. 6th Edition.Wadsworth Cengage Learning, USA.

Hoffman, M. D. \& Stuempfle, K. J. (2015). Sodium supplementation and exerciseassociated hyponatremia during prolonged exercise. Medicine \& Science in Sports and Exercise, 47(9), 1781-1787.

Hall, K. D., Heymsfield, S. B., Kemnitz, J. W., Klein, S., Schoeller, D. A. \& Speakman, J. R. (2012). Energy balance and its components: implications for body weight regulation. The American Journal of Clinical Nutrition, 95,989-994.
Ismail, I., Singh, R. \& Sirisinghe, R. (2007). Rehydration with sodium-enriched coconut water after exercise-induced dehydration. Southeast Asian Journal of Tropical Medicine and Public Health, 38, 769-785.

James, L. J., Mears, S. A. \& Shirreffs, S. M. (2015). Electrolyte supplementation during severe energy restriction increases exercise capacity in the heat. European Journal of Applied Physiology, 115(12), 2621-2629.

Jentjens, R. \& Jeukendrup, A. E. (2003). Determinants of post-exercise glycogen synthesis during short-term recovery. Sports Medicine, 33, 117-144.

Jentjens, R. L. \& Jeukendrup, A. E. (2005). High rates of exogenous carbohydrate oxidation from a mixture of glucose and fructose ingested during prolonged cycling exercise. British Journal of Nutrition, 93, 485-492.

Jeukendrup, A. E. (2010). Carbohydrate and exercise performance: the role of multiple transportable carbohydrates. Current Opinion in Clinical Nutrition \& Metabolic Care, 13, 452-457.

Judelson, D. A., Maresh, C. M., Yamamoto, L. M., Farrell, M. J., Armstrong, L. E., Kraemer, W. J., Volek, J. S., Spiering, B. A., Casa, D. J. \& Anderson, J. M. (2008). Effect of hydration state on resistance exerciseinduced endocrine markers of anabolism, catabolism, and metabolism. Journal of Applied Physiology, 105, 816-824.

Mack, G. W. \& Nadel, E. R. (2011). Body fluid balance during heat stress in humans. Environmental Physiology, 14,187-214.

Moniruzzaman, M., Khalil, M. I., Sulaiman, S.A. \& Gan, S. H. (2013). Physicochemical and antioxidant properties of Malaysian honey produced by Apis cerana, Apis dorsata, and Apis mellifera. BMC Complementary and Alternative Medicine, 13, 43-55.

Naclerio, F., Larumbe-Zabala, E., Ashrafi, N., Seijo, M., Nielsen, B., Allgrove, J. \& Earnest, C.P. (2017). Effects of proteincarbohydrate supplementation on immunity 
and resistance training outcomes: a doubleblind, randomized, controlled clinical trial. European Journal of Applied Physiology, 117(2), 267-277.

Nybo, L. (2008) Hyperthermia and fatigue. Journal of Applied Physiology, 104, 871878.

Ormsbee, M. J., Bach, C. W. \& Baur, D. A. (2014). Pre-exercise nutrition: the role of macronutrients, modified starches, and supplements on metabolism and endurance performance. Nutrients, 6, 1782-1808.

Peeling, P., Binnie, M. J., Goods, P. S., Sim, M. \& Burke, L. M. (2018). Evidence-based supplements for the enhancement of athletic performance. International Journal of Sport Nutrition and Exercise Metabolism, 28(2), 178-187.

Peinado, A. B., Rojo-Tirado, M. A. \& Benito, P. J. (2013). Sugar and physical exercise; the importance of sugar for athletes. Nutrición Hospitalaria, 28, 48-56.

Popli, S., Tzamaloukas, A. H. \& Ing, T. S. (2014). Osmotic diuresis-induced hypernatremia: better explained by solutefree water clearance or electrolyte-free water clearance? International Urology and Nephrology, 46, 207-210.

Rehrer, N. J. (2001). Fluid and electrolyte balance in ultra-endurance sport. Sports Medicine, 31, 701-715.

Rakova, N., Kitada, K., Lerchl, K., Dahlmann,A., Birukov, A., Daub, S., Kopp, C., Pedchenko, T., Zhang, Y., Beck, L. \& Johannes, B. (2017). Increased salt consumption induces body water conservation and decreases fluid intake. The Journal of Clinical Investigation, 127(5), 1932-1943.

Sharp, R. L. (2006). Role of sodium in fluid homeostasis with exercise. Journal of the American College of Nutrition, 25, 231239.

Shirreffs, S. M., Taylor, A. J., Leiper, J. B. \& Maughan, R. J. (1996). Post-exercise rehydration in man: effects of volume consumed and drink sodium content. Medicine and Science in Sports and Exercise, 28, 1260-1271.

Van Beaumont, W., Underkofler, S. \& Van Beaumont, S. (1981). Erythrocyte volume, plasma volume, and acid-base changes in exercise and heat dehydration. Journal of Applied Physiology, 50, 1255-1262.

Wilson, T. \& Temple, N. J. (2003) Beverages in Nutrition and Health. Springer Science \& Business Media, New York.

Wingo, J. E., Low, D. A., Keller, D. M., Brothers, R. M., Shibasaki, M. \& Crandall, C. G. (2010), Skin blood flow and local temperature independently modify sweat rate during passive heat stress in humans. Journal of Applied Physiology, 109, 13011306.

Wong, H. S. \& Chen, Y. (2011). Effect of a carbohydrate-electrolyte beverage, lemon tea, or water on rehydration during shortterm recovery from exercise. International Journal of Sports Nutrition and Exercise Metabolism, 21, 300-310. 